\title{
Aniseikonia associated with epiretinal membranes
}

\author{
M Ugarte, T H Williamson
}

Br J Ophthalmol 2005;89:1576-1580. doi: 10.1136/bjo.2005.077164

\begin{abstract}
Aims: To determine whether the computerised version of the new aniseikonia test (NAT) is a valid, reliable method to measure aniseikonia and establish whether aniseikonia occurs in patients with epiretinal membranes (ERM) with preserved good visual acuity.

Methods: With a computerised version of the NAT, horizontal and vertical aniseikonia was measured in 16 individuals (mean 47 (SD 16.46) years) with no ocular history and 14 patients (mean 67.7 (14.36) years) with ERM. Test validity was evaluated by inducing aniseikonia with size lenses. Test reliability was assessed by the test-retest method. Results: In normal individuals, the mean percentage (SD) aniseikonia was $-0.24 \%(0.71)$ horizontal and $0 \%(0.59)$ vertical. Validity studies revealed mean (SD) 0.990 (0.005) horizontal and $0.991(0.004)$ vertical correlation coefficients, $0.985(0.111)$ horizontal and 0.989 (0.102) vertical slope. Repeatability coefficients were 1.04 horizontal and 0.88 vertical. Aniseikonia in patients with ERM ranged from $4 \%$ to $14 \%$. Eight patients showed $2 \%$ or more size difference between horizontal and vertical meridians.

Conclusions: The aniseikonia test used in this study can be considered a simple, fast, valid and reliable method to measure the difference in image size perceived by each eye. Aniseikonia does occur in symptomatic patients with ERM. The effect of ERM on image size is heterogeneous across the retinal area affected.
\end{abstract}

E piretinal membranes (ERM) are non-vascular fibrocellular proliferations on the retinal inner surface. They develop either spontaneously, in association with ocular diseases (for example, retinal detachment, chorioretinitis, retinal vein occlusions), or following surgery (for example, scleral buckling, cataract extraction, retinal cryopexy). The 5 year Blue Mountain Study found a 5.3\% cumulative incidence of spontaneous ERM above the age of 49. ${ }^{1}$ ERM are generally located in the macula and their ability to contract $^{2}$ can distort the photoreceptor distribution in the fovea. This would affect image perception causing an object to appear larger (macropsia) or smaller (micropsia). Some of the symptoms in patients with ERM may result from aniseikonia (Greek: anisos, unequal; eikon, image) or the perception of the same image as being of different size with each eye. A few studies have reported aniseikonia in macular disease such as ERM, ${ }^{3}{ }^{4}$ vitreoretinal traction, ${ }^{4}$ and central serous retinopathy. ${ }^{5}$ However, the prevalence of aniseikonia in ERM is unknown since it is not tested routinely in the clinic.

Aniseikonia can be measured by two dimensional and three dimensional methods. The space eikonometer ${ }^{6}$ depends on the observed effect of size lenses on a three dimensional array of cords and rods. It is very accurate but the information provided is difficult to interpret. The use of the instrument was discontinued in the 1970s. A simplified test consisting of graded stereoscopic cards reproducing the space eikonometer target was developed later on. ${ }^{7}$ The performance of this test requires good stereopsis. This is known to be reduced in patients with aniseikonia, making its results unreliable. The NAT measures aniseikonia directly, by presenting a red and a green semicircle to each eye by means of dissociation with red/green goggles. It is easy and rapid to perform ${ }^{28}$ and we consider it ideal for clinical use. We used a computerised version of the NAT after confirming its validity and reliability to measure aniseikonia in symptomatic patients with unilateral macular ERM.

\section{MATERIALS AND METHODS}

Sixteen volunteers, mean age 47 (SD 16.46), 10 women and six men, without ocular history and less than 1 dioptre (D) anisometropia were included in the control group. Fourteen patients, mean age 67.7 (SD 14.36), five women and nine men, with ERM were recruited between October 2003 and December 2004. Inclusion criteria were visual complaints, less than $1 \mathrm{D}$ anisometropia, logarithmic minimum angle of resolution ( $\log$ MAR) visual acuity (VA) 0.5 or better in each eye, and unilateral macular ERM. The research carried out followed the tenets of the World Medical Association Declaration of Helsinki. Subjects underwent ocular examination, refraction, best corrected VA, orthoptic assessment, metamorphopsia analysis with Amsler chart, threshold horizontal and vertical aniseikonia measurement, slit lamp examination, and funduscopy.

The computerised NAT consisted of matched pairs of red/ green semicircles with a white, round fixation target on a black background. The fixation target was $3 \mathrm{~cm}$ in diameter and the red semicircle $15 \mathrm{~cm}$. The diameter of the green semicircle varied in $1 \%$ steps (from $-14 \%$ to $+14 \%$ ). Subjects viewed the monitor from $66 \mathrm{~cm}$ with appropriate correction and red/green goggles. The white target projected an image $1.5^{\circ}$ around fixation and the red semicircle $7.5^{\circ} ; 1 \%$ variation in the green semicircle diameter corresponded to $0.15^{\circ}$ (9 minutes of arc) increases/decreases in retinal image size. Two series of matched semicircles (horizontal and vertical) were presented at random. The individual had to identify the pair in which both semicircles appeared equal in size. The size difference represented the percentage of aniseikonia. Threshold aniseikonia was measured by bracketing. Different pairs were shown reversing about threshold. The average of three reversals was taken as the threshold.

The precision of our measurements was assessed by evaluating the test validity and reliability. Validity was analysed by calculating the agreement between our measurements and the true value obtained by inducing micropsia/ macropsia in one eye of the 16 controls using four size lenses (magnification $(\mathrm{m}):+3 \%,+5 \%,+7 \%$ and $+9 \%$, spectacle magnification $(M), M=1+(\mathrm{m} / 100): 1.03,1.05,1.07$, and 1.09, respectively). By placing the concave or convex lens surface facing the eye the image size was increased or

Abbreviations: ERM, epiretinal membranes; NAT, new aniseikonia test; $\mathrm{VA}$, visual acuity 
Table 1 Profile and clinical characteristics of subjects in the control group

\begin{tabular}{|c|c|c|c|c|c|c|}
\hline \multirow{2}{*}{$\begin{array}{l}\text { Control } \\
\text { No }\end{array}$} & \multirow[b]{2}{*}{ Sex } & \multirow{2}{*}{$\begin{array}{l}\text { Age } \\
\text { (years) }\end{array}$} & \multicolumn{2}{|l|}{ Right eye } & \multicolumn{2}{|l|}{ Left eye } \\
\hline & & & Refraction (D) & VA & Refraction (D) & VA \\
\hline 1 & $\mathrm{~F}$ & 20 & Plano & -0.1 & Plano & -0.1 \\
\hline 2 & $M$ & 26 & Plano & -0.2 & Plano & -0.2 \\
\hline 3 & $\mathrm{~F}$ & 27 & Plano & -0.1 & Plano & -0.1 \\
\hline 4 & M & 31 & Plano & -0.2 & Plano & -0.2 \\
\hline 5 & $\mathrm{~F}$ & 37 & -0.50 sphere & -0.2 & $-0.50 /-0.25 \times 025$ & -0.2 \\
\hline 6 & $\mathrm{~F}$ & 40 & $-2.75 /-0.5 \times 056$ & -0.1 & $-3.25 /-0.75 \times 014$ & 0 \\
\hline 7 & M & 43 & Plano & -0.1 & -0.50 sphere & 0.1 \\
\hline 8 & M & 47 & $+0.75 /-0.75 \times 176$ & -0.1 & $+1.00 /-0.25 \times 121$ & -0.1 \\
\hline 9 & $\mathrm{~F}$ & 50 & $\begin{array}{l}\text { Plano } \\
\text { Add }+2.00\end{array}$ & -0.1 & $\begin{array}{l}\text { Plano } \\
\text { Add }+1.75\end{array}$ & -0.1 \\
\hline 10 & $\mathrm{~F}$ & 51 & $\begin{array}{l}\text { Plano } \\
\text { Add }+2.00\end{array}$ & -0.1 & $\begin{array}{l}\text { Plano } \\
\text { Add }+2.00\end{array}$ & -0.1 \\
\hline 11 & $\mathrm{~F}$ & 53 & $\begin{array}{l}+1.50 /-0.50 \times 094 \\
\text { Add }+2.00\end{array}$ & -0.1 & $\begin{array}{l}+1.50 \text { sphere } \\
\text { Add }+2.00\end{array}$ & -0.2 \\
\hline 12 & M & 55 & $\begin{array}{l}\text { Plano } \\
\text { Add }+2.00\end{array}$ & -0.1 & $\begin{array}{l}\text { Plano } \\
\text { Add }+2.00\end{array}$ & -0.1 \\
\hline 13 & $\mathrm{~F}$ & 59 & $-0.75 /-1.25 \times 067$ & -0.1 & -0.75 & -0.1 \\
\hline 14 & M & 66 & $\begin{array}{l}\text { Plano } \\
\text { Add }+3.00\end{array}$ & +0.1 & $\begin{array}{l}\text { Plano } \\
\text { Add }+3.00\end{array}$ & +0.1 \\
\hline 15 & $\mathrm{~F}$ & 69 & $\begin{array}{l}\text { Plano } \\
\text { Add }+2.75\end{array}$ & -0.1 & $\begin{array}{l}\text { Plano } \\
\text { Add }+2.50\end{array}$ & 0 \\
\hline 16 & $\mathrm{~F}$ & 78 & $\begin{array}{l}+0.50 /-1.00 \times 049 \\
\text { Add }+3.00\end{array}$ & -0.1 & $\begin{array}{l}-0.50 /-2.00 \times 074 \\
\text { Add }+3.00\end{array}$ & -0.1 \\
\hline Mean (SD) & \multicolumn{2}{|c|}{$47(16.46)$} & & $-0.1(0.07)$ & & $-0.1(0.10)$ \\
\hline
\end{tabular}

reduced, respectively. Correlation coefficient, the slope of the best fit linear regression, and $y$ axis intercept were calculated. Reliability was examined by measuring agreement between repeated measurements ${ }^{9}$ recorded 2 weeks apart on 10 control individuals (20-69 years old). The magnification used in reliability studies was $-9 \%,-5 \%, 0 \%,+5 \%$, and $+9 \%$. The coefficient of repeatability ${ }^{10}$ was calculated. The unpaired $t$ test was used to compare aniseikonia results in controls and patients.

\section{RESULTS}

A summary of the ophthalmic examination of the 16 controls and 14 patients with unilateral ERM is shown in tables 1 and 2. The logMAR VA (mean (SD)) was $-0.1(0.1)$ in the controls, $0.18(0.25)$ in the eye with ERM in our patients, and $0(0.13)$ in the unaffected eye. All patients with ERMs had visual symptoms.

The NAT validity was assessed by comparing our measurements with the true value obtained by inducing increments/ reductions $(-9 \%,-7 \%,-5 \%,-3 \%, 0 \%,+3 \%,+5 \%,+7 \%$, and $+9 \%$ ) in the green semicircle using size lenses (fig 1). This revealed (mean (SD)): (1) correlation coefficient of 0.990 (0.005) for horizontal and 0.991 (0.004) vertical aniseikonia, confirming the agreement between our measurements and its true value; (2) slope of 0.985 (0.111) horizontal and 0.989 (0.102) vertical aniseikonia, suggesting there is a small underestimation, (3) y axis intercept of -0.08 (0.468) horizontal and $-0.06(0.339)$ vertical. The test-retest method revealed coefficient of repeatability, 1.04 horizontal and 0.88 vertical (table 3 ). In both meridians the differences between readings 1 and 2 were within 2 SD of the mean. The results from this test can, therefore, be considered reproducible and reliable.

The range of horizontal and vertical threshold aniseikonia in patients with unilateral ERM was 4-14\% (fig 2). Eleven patients perceived the image of the affected eye as larger and three as smaller than in the fellow eye. In eight patients, there was $2 \%$ or more difference between the amount of

(Mean (SD))
Correlation coefficient $0.990(0.005)$
Slope: $0.985(0.111)$
Y axis intercept: $-0.08(0.468)$

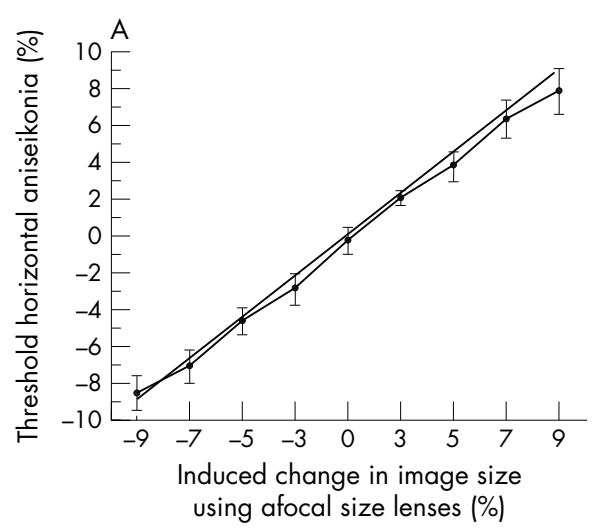
using afocal size lenses (\%)

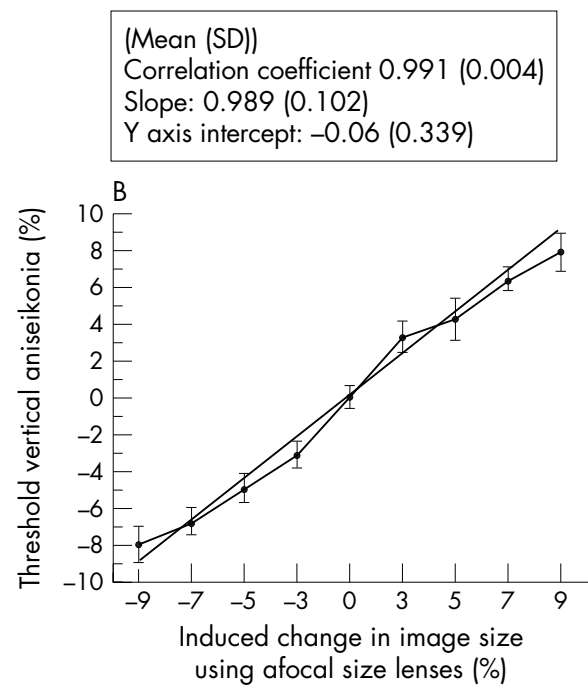

Figure 1 Horizontal (A) and vertical (B) aniseikonia measured in 16 normal subjects after inducing changes in the green semicircle size (magnification (m): $-9 \%,-7 \%,-5 \%,-3 \%, 3 \%, 5 \%$, $7 \%$, and $9 \%$ ) with size lenses. The straight line represents the ideal test, 1 correlation coefficient, 1 slope and $Y$ axis intercept at 0 .

\section{(Mean (SD))}

Slope: 0.989 (0.102)

Y axis intercept: $-0.06(0.33$

using afocal size lenses (\%) 


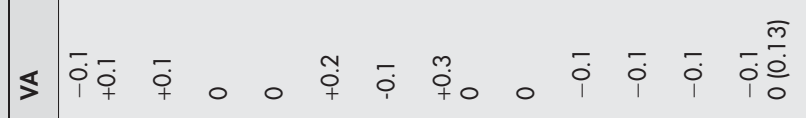

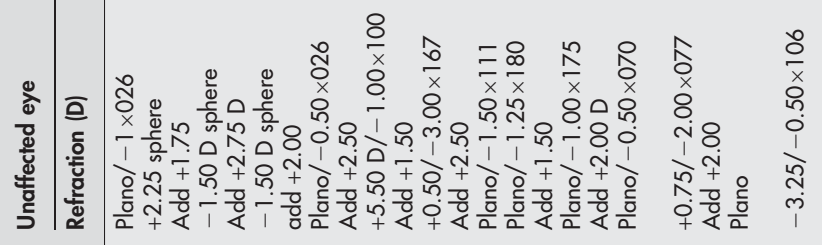

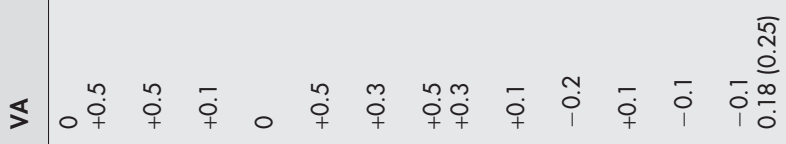

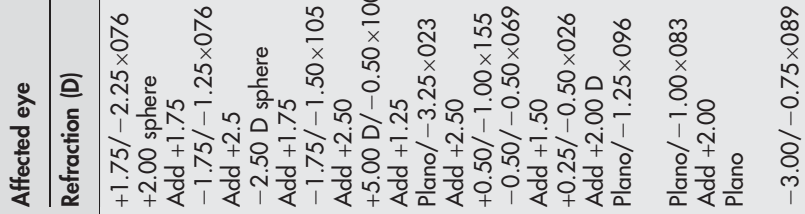
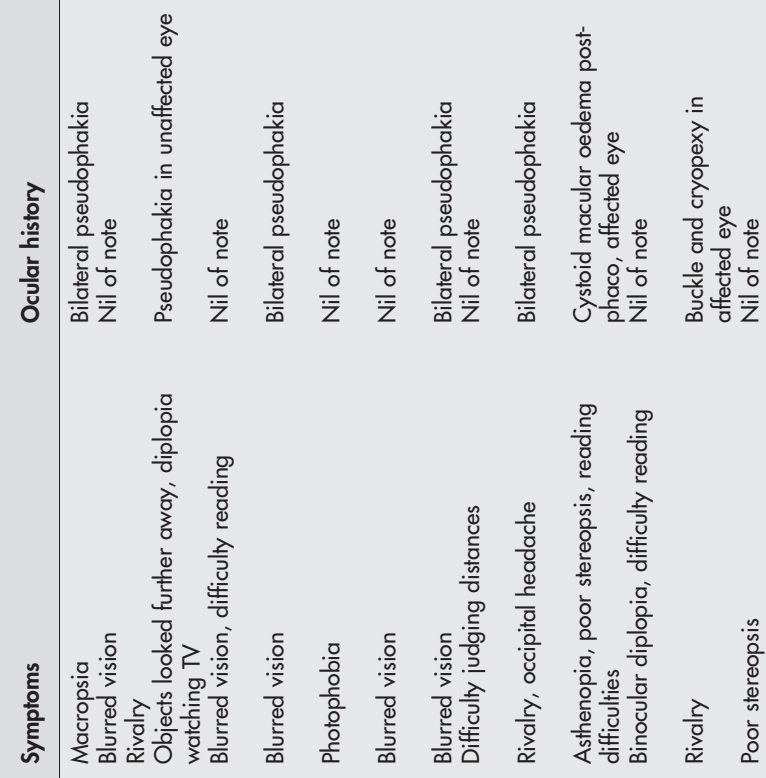

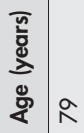

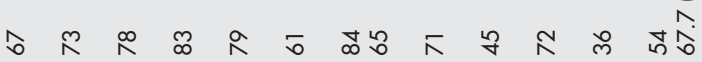

×

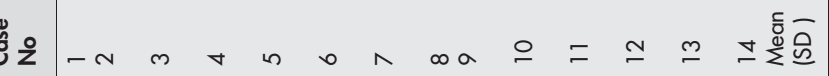

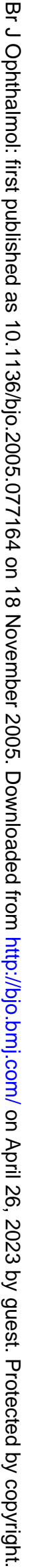


Table 3 Assessment of agreement between repeated measurements of horizontal (A) and vertical (B) threshold aniseikonia

\begin{tabular}{|c|c|c|c|c|}
\hline & \multirow{2}{*}{$\frac{\text { 1st reading }}{\text { Mean (SD) }}$} & \multirow{2}{*}{$\begin{array}{l}\text { 2nd reading } \\
\text { Mean (SD) }\end{array}$} & \multirow{2}{*}{$\begin{array}{l}\text { Difference } \\
\text { between } \\
\text { readings }\end{array}$} & \multirow{2}{*}{$\begin{array}{l}\text { Coefficient of } \\
\text { repeatability }\end{array}$} \\
\hline & & & & \\
\hline \multicolumn{5}{|c|}{ (A) Induced horizontal aniseikonia with size lenses } \\
\hline$-9 \%$ & $-8.4(1.10)$ & $-7.8(0.54)$ & $1(0.53)$ & 1.05 \\
\hline$-5 \%$ & $-4.5(0.47)$ & $-4.7(0.42)$ & $0.3(0.42)$ & 0.84 \\
\hline $0 \%$ & $-0.2(0.59)$ & $-0.05(0.55)$ & $0.5(0.53)$ & 1.05 \\
\hline $5 \%$ & $4.0(0.71)$ & $4.3(0.63)$ & $0.5(0.41)$ & 0.82 \\
\hline $9 \%$ & $8.0(1.07)$ & $8.1(0.96)$ & $0.6(0.52)$ & 1.03 \\
\hline Mean (SD) & & & $0.58(0.519)$ & $1.03(0.119)$ \\
\hline \multicolumn{5}{|c|}{ (B) Induced vertical aniseikonia with size lenses } \\
\hline$-9 \%$ & $-7.8(1.14)$ & $-7.9(0.85)$ & $0.7(0.53)$ & 1.06 \\
\hline$-5 \%$ & $-4.6(0.83)$ & $-4.7(0.42)$ & $0.3(0.42)$ & 0.88 \\
\hline $0 \%$ & $0.1(0.62)$ & $0.3(0.43)$ & $0.45(0.37)$ & 0.74 \\
\hline $5 \%$ & $4.7(1.13)$ & $4.5(1.10)$ & $0.5(0.41)$ & 0.82 \\
\hline $9 \%$ & $8.1(0.70)$ & $7.8(0.48)$ & $0.8(0.42)$ & 0.84 \\
\hline Mean (SD) & & & $0.57(0.440)$ & $0.84(0.119)$ \\
\hline
\end{tabular}

aniseikonia detected in the vertical and horizontal meridians. The unpaired $t$ test comparing horizontal and vertical aniseikonia in controls and patients with ERMs revealed $\mathrm{p}=0.0419$ and $\mathrm{p}=0.0024$, respectively.

\section{DISCUSSION}

ERM can alter retinal morphology ${ }^{11}$ and function. ${ }^{1-14}$ The compression, separation, and/or tilt of photoreceptors can result in the perception of an image as being larger (macropsia)/smaller (micropsia) and simultaneous stimulation of corresponding retinal regions by uncorrelated images. If one of them is not suppressed the inability to integrate information from each eye can cause an extremely confusing experience. We propose that some of the symptoms in ERM may be due to aniseikonia, a condition in which each eye perceives the same image as being of different size.

It is essential to have clinical methods to measure aniseikonia accurately. In this study, we used a computerised

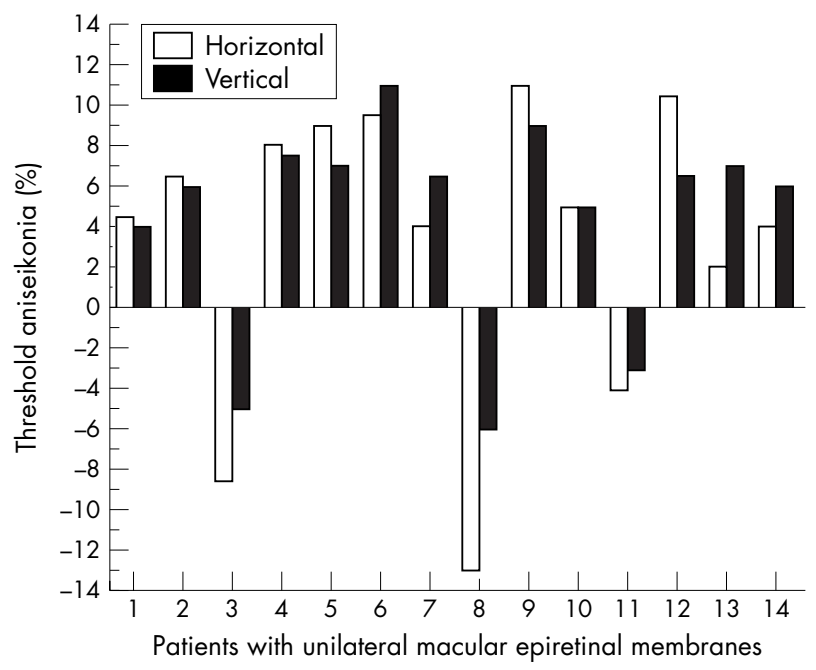

Figure 2 Horizontal and vertical aniseikonia (\%) measured in 14 patients with unilateral macular ERMs. In 11 patients the image perceived by the affected eye was larger than in the fellow eye (macropsia) and in the remaining three, the eye with the ERM detected images as smaller (micropsia). Eight patients demonstrated $2 \%$ or more difference in image size between horizontal and vertical meridia. version of the NAT after confirming its validity and repeatibility. Validity, the extent to which the test measures what it purports to measure, was evaluated by inducing aniseikonia with size lenses in 16 controls and comparing our measurements with the true value. Correlation coefficients (mean (SD)) were 0.990 (0.005) horizontal and 0.991 (0.004) vertical, in good accordance with studies by others. ${ }^{8}{ }^{15}$ Horizontal and vertical slope (mean (SD)) was 0.985 $(0.111)$ and $0.989(0.102)$, respectively, suggesting a small underestimation. In this context, NAT comparisons with the space eikonometer ${ }^{16}$ and phase difference haploscope ${ }^{17}$ have also shown an underestimation. This may be due to a greater sensory fusion range when dissociating with red/green anaglyphs. The Y axis intercepts (representing "inherent" aniseikonia) (mean (SD)) were $-0.08(0.468)$ horizontal and $-0.06(0.339)$ vertical. Repeatability coefficients were 1.04 horizontal and 0.88 vertical; $1 \%$ difference in target size corresponds to $0.15^{\circ}$ or 9 minutes of arc variation in the retinal image size projected $7.5^{\circ}$ around fixation. The logarithmic VA (mean (SD)) in the centre of the fovea of our controls was -0.1 (0.01) (equivalent to 0.75 minutes of arc minimal angle of resolution). Given that the VA reduces as a function of eccentricity ${ }^{18} ; 7.5^{\circ}$ away from the fovea the VA would be about $10-20 \%$ of the maximum (5-10 minutes of arc); therefore, repeatability coefficients of 1.04 and 0.88 can be considered acceptable.

Threshold aniseikonia (mean (SD)) in controls was $-0.24 \%(0.71 \%)$ horizontal and $0 \%(0.59 \%)$ vertical. Several studies have advocated different values of "normal" aniseikonia based on binocular fusion tolerance thresholds (1.5\%, ${ }^{19}$ $5-8 \%,{ }^{20}$ and $18 \%{ }^{21}$ ). This great variation could depend on the type of aniseikonia investigated (for example, axial or refractive anisometropia) or the method used (target size, distance from target). It would, therefore, be advisable to standardise the methodology in order to be able to compare results. In symptomatic patients with unilateral ERMs $(\mathrm{n}=14)$ aniseikonia ranged from $4 \%$ to $14 \%$, similar to other studies. ${ }^{3}$ Because of the heterogeneous shape of epiretinal proliferation the effect on retinal morphology would be expected to vary across the area affected. This was confirmed by a more than $2 \%$ difference in horizontal and vertical aniseikonia in eight patients. This heterogeneity implies that the compensatory mechanisms of the visual system or optical correction with iseikonic lenses would be ineffective. In our own experience, surgical removal of ERM improves 
micropsia/macropsia. Further studies are currently being carried out by us to determine the effect of surgical intervention on image size, aniseikonia, and patients' symptoms.

The results presented here support the idea that the computerised version of the NAT is a simple, fast, reliable method to measure aniseikonia clinically. Aniseikonia occurs in symptomatic patients with macular ERMs with good VA. The change in image size caused by the ERM is heterogeneous across the retinal area being distorted. This can result in intolerable symptoms when working with both eyes simultaneously.

\section{ACKNOWLEDGEMENT}

The authors thank Mr Ken Clarke for his invaluable help with the computer program of the MAT.

\section{Authors' affiliations}

M Ugarte, T H Williamson, Department of Ophthalmology, Queen Mary's Hospital, Sidcup, Kent DA14 6LT and St Thomas's Hospital, London SEI 7EH, UK

Correspondence to: Marta Ugarte, Department of Ophthalmology, St Thomas's Hospital, London SE1 7EH, UK; mugarte@doctors.org.uk

Accepted for publication 28 July 2005

\section{REFERENCES}

1 Fraser-Bell S, Guzowski M, Rochtchina E, et al. Five-year cumulative incidence and progression of epiretinal membranes: the Blue Mountains Eye Study. Ophthalmology 2003;11:34-40.

2 Smiddy WE, Maguire AM, Green WR, et al. Idiopathic epiretinal membranes: ultrastructural characteristics and clinicopathologic correlation. Ophthalmology 1989;96:811-20

3 Enoch JM, Schwartz A, Chang D, et al. Aniseikonia, metamorphopsia and perceived entoptic pattern: some effects of a macular epiretinal membrane, and the subsequent spontaneous separation of the membrane. Ophthalmic Physiol Opt 1995; 15:339-43.

4 Benegas NM, Egbert J, Engel WK, et al. Diplopia secondary to aniseikonia associated with macular disease. Arch Ophthalmol 1999;117:896-9.

5 Hisada H, Awaya S. Aniseikonia of central serous chorioretinopathy. Nippon Ganka Gakkai Zasshi 1992;96:369-74. (Abstract).

6 www.dartmouth.edu.

7 www.keystoneview.com.

8 Awaya S, Sugawara M, Horibe F, et al. The "new aniseikonia tests" and its clinical applications (author's transl). Nippon Ganka Gakkai Zasshi 1982;86:217-22.

9 Bland JM, Altman DG. Statistical methods for assessing agreement between two methods of clinical measurement. Lancet 1986;1:307-10.

10 British Standards Institution. Precision of test methods I: Guide for the determination and reproducibility for a standard test method (BS 5497, part 1). London: BSI

11 Wilkins JR, Puliafito CA, Hee MR, et al. Characterization of epiretinal membranes using optical coherence tomography. Ophthalmology 1996;103:2142-51.

12 Niwa T, Terasaki $H$, Kondo $M$, et al. Function and morphology of macula before and after removal of idiopathic epiretinal membrane. Invest Ophthalmol Vis Sci 2003;44:1652-6.

13 Suzuki T, Terasaki H, Niwa T, et al. Optical coherence tomography and focal macular electroretinogram in eyes with epiretinal membrane and macular pseudohole. Am J Ophthalmol 2003;136:62-7.

14 Gass JD. Stereoscopic atlas of macular diseases: diagnoses and treatment. 4th ed. St Louis: Mosby, 1997.

15 de Wit GC. Evaluation of a new direct-comparison aniseikonia test. Binocul Vis Strabismus Q 2003;18:87-94.

16 McCormack G, Peli E, Stone P. Differences in tests of aniseikonia. Invest Ophthalmol Vis Sci 1992;33:2063-7.

17 Ogle KN, Burian HM, Bannon RE. On the correction of unilateral aphakia with contact lenses. AMA Arch Ophthalmol 1958;59:639-52.

18 Westheimer G. Adler's physiology of the eye. 9th ed. Hart WM, ed. St Louis: Mosby Year Book, 1992:531-47.

19 Crone RA, Leuridan OM. Tolerance for aniseikonia. I. Diplopia thresholds in the vertical and horizontal meridians of the visual field. Albrecht Von Graefes Arch Klin Exp Ophthalmol 1973;31;188:1-16.

20 Lubkin V, Kramer P, Meininger D, et al. Aniseikonia in relation to strabismus, anisometropia and amblyopia. Binocul Vis Strabismus $Q$ 1999; 14:203-7.

21 Berger A, Monje M. Uber den Einfluss der Aniseikonie auf Tifensehen. Albrecht von Graefes Arch Klin Exp Ophthalmol 1948;148:515-28. 